\title{
Tratamento Contábil dos Ativos Biológicos e Produtos Agrícolas em Cooperativas de Santa Catarina ${ }^{1}$
}

\author{
Accounting Treatment of Biological Assets and Agricultural \\ Cooperative in Santa Catarina
}

\section{Tratamiento Contable de los Activos Biológicos y Productos Agrícolas Cooperativa de Santa Catarina}

\author{
Silvana Dalmutt Kruger, Me. \\ Doutoranda Programa de Pós-Graduação em Ciências Contábeis - \\ UFSC, Endereço: Universidade Comunitária da Região de Chapecó, \\ Senador Atílio Fontana, Efapi, CEP: 89809000 - Chapecó, SC - Brasil - \\ Caixa-postal: 747, Telefone: (49) 3321-8243, e-mail: \\ silvanak@unochapeco.edu.br \\ Sady Mazzioni, Me. \\ Doutorado Programa de Pós-Graduação em Ciências Contábeis e \\ Administração - FURB, Brasil. \\ Endereço: Universidade Comunitária da Região de Chapecó, Área de \\ Ciências Sociais Aplicadas. Avenida Senador Attílio Fontana 591 E, \\ Bloco R, EFAPI, CEP: 89.809-000, Chapecó, SC - Brasil, Telefone: (49) \\ 3321-8243, e-mail: sady@unochapeco.edu.br
}

\author{
Andrea Bordignon, Esp. \\ Endereço: Universidade Comunitária da Região de Chapecó \\ Senador Atílio Fontana, Efapi, CEP: 89809000 - Chapecó, SC - Brasil - \\ Caixa-postal: 747, Telefone: (49) 3321-8243 \\ e-mail: andreacb@unochapeco.edu.br \\ Clésia Ana Gubiani, Me. \\ Endereço: Universidade Comunitária da Região de Chapecó \\ Senador Atílio Fontana, Efapi, CEP: 89809000 - Chapecó, SC - Brasil - \\ Caixa-postal: 747, Telefone: (49) 3321-8243 \\ e-mail: clesia@unochapeco.edu.br
}

\section{RESUMO}

O Pronunciamento Técnico CPC 29 regulamenta os critérios de reconhecimento, mensuração e evidenciação dos ativos biológicos e produtos agrícolas. O estudo tem por objetivo evidenciar se as práticas contábeis adotadas por Cooperativas Agropecuárias de Santa Catarina atendem às exigências do Pronunciamento Técnico CPC 29. Os procedimentos metodológicos utilizados caracterizam a pesquisa como descritiva, documental e qualitativa. A análise foi realizada a partir do conjunto de relatórios anuais elaborados pela amostra composta por nove cooperativas agropecuárias que disponibilizaram as informações. Os resultados do estudo, por meio da análise do check list realizado, evidencia que $89 \%$ das cooperativas indicam a natureza e as características dos ativos biológicos e produtos agrícolas que possuem, embora apenas $22 \%$ delas evidenciam o método e as premissas aplicadas na determinação do valor justo dos ativos biológicos e produtos agrícolas; $89 \%$ mensuram os ativos biológicos pelo custo, menos depreciação e perda recuperável acumulada; $44 \%$ mensuram os produtos agrícolas com base no valor de mercado ativo e apenas $33 \%$ das cooperativas divulgaram os ganhos ou perdas do período em relação aos ativos biológicos. Diante dos resultados, observa-se que o Pronunciamento Técnico CPC 29 ainda está em fase de adaptação pelas Cooperativas Agropecuárias de Santa Catarina.

Palavras-chave: CPC 29. Ativos Biológicos. Produtos Agrícolas.

\section{ABSTRACT}

The CPC 29 governs the criteria for recognition, measurement and disclosure of biological assets and agricultural products. The study aims to highlight the accounting practices adopted by Agricultural Cooperatives of Santa Catarina meet the requirements of CPC 29. The methodological procedures used to characterize research as descriptive, documentary and qualitative. The analysis was conducted from the set of annual reports by the sample consists of nine agricultural cooperatives that provided the information. The results of the study, through the analysis of the checklist done, shows that $89 \%$ of cooperatives indicate the nature and characteristics of biological assets and agricultural products that have, although only $22 \%$ of them show the method and assumptions applied in determining the fair value of biological assets

\footnotetext{
${ }^{1}$ Artigo recebido em 13.05.2014. Revisado pelos pares em 05.08.2014 (blind review). Ajustado e Aceito para publicação em 06.12.2014. Recomendado para publicação por José Ribamar Marques de Carvalho (Editor Científico). Publicado em 30.12.2014. Organização responsável CCJS/UFCG.
} 
and agricultural products, $89 \%$ measure biological assets at cost less accumulated depreciation and recoverable loss, $44 \%$ measure agricultural products based on the market value of assets and only 33\% of cooperatives reported gains or losses period in relation to biological assets. Given the results, it is observed that CPC 29 is still being adapted by Agricultural Cooperatives of Santa Catarina.

Keywords: CPC 29. Biological Assets. Agricultural Products.

RESUMEN

El Pronunciamiento regula los criterios de valoración, presentación y revelación de los activos biológicos y productos agrícolas. El estudio pretende demostrar que las prácticas contables adoptadas por Cooperativas Agrarias de Santa Catarina cumplen los requisitos de la NIC 29. Los procedimientos metodológicos utilizados caracterizaron la investigación como descriptivo, documental y cualitativa. El análisis se realizó a partir del conjunto de informes anuales de la muestra se compone de nueve cooperativas agrícolas que proporcionaron la información. Los resultados del estudio, a través de la lista de verificación de los análisis realizados muestran que el $89 \%$ de las cooperativas indican la naturaleza y las características de los activos biológicos y productos agrícolas tienen, aunque sólo el 22\% de ellos muestran el método y los supuestos utilizados en la determinación de la valor razonable de los activos biológicos y productos agrícolas; 89\% medida los activos biológicos a su costo menos la depreciación y pérdidas por deterioro acumulada; $44 \%$ medida productos agrícolas basados en el valor activo del mercado y sólo el 33\% de las cooperativas reportaron ganancias o pérdidas para el período en relación con los activos biológicos. Dados los resultados, se observa que el CPC 29 está todavía en el proceso de adaptación de las Cooperativas Agrarias de Santa Catarina.

Palabras clave: CPC 29. Activos Biológicos. Productos Agrícolas.

\section{INTRODUÇÃO}

Diversas alterações foram introduzidas na contabilidade brasileira a partir do conjunto de Pronunciamentos Técnicos emitidos pelo Comitê de Pronunciamentos Contábeis e regulamentados em Normas Brasileiras de Contabilidade pelo Conselho Federal de Contabilidade (CFC). O conjunto de Pronunciamentos Técnicos (CPCs) introduziu modificações na forma de mensuração e evidenciação do conjunto patrimonial visando a harmonização aos padrões internacionais das International Financial Reporting Standards -IFRS.

O Pronunciamento Técnico CPC 29 (2009) trata da regulamentação, mensuração e evidenciação dos ativos biológicos (conjunto de animais e plantas vivos) e produtos agrícolas (derivados da colheita de ativos biológicos) e segue as orientações da International Accounting Standard 41 - Agriculture (IASB, 2009). Conforme a IAS 41 e o CPC 29 os ativos biológicos e produtos agrícolas devem ser mensurados pelo valor justo.

Ernst \& Young Terco; Fipecafi (2010) enfatizam que as novas exigências relacionadas aos ativos biológicos tornam-se relevantes à medida que as entidades divulgarem a descrição desses ativos e as suas respectivas formas de avaliação, visando à evidenciação dos critérios de mensuração adotados para os diversos usuários das demonstrações contábeis.

Rech e Pereira (2012) destacam a importância da mensuração dos ativos biológicos, possibilitando a evidenciação com fidedignidade do patrimônio das entidades rurais. No entanto, ressaltam a suscitação de uma série de divergências na mensuração dos ativos e passivos pelo valor justo, em decorrência da subjetividade deste conceito.

Apesar da recente adoção do CPC 29 (2009), o estudo dos critérios de mensuração e evidenciação dos ativos biológicos se justifica pela relevância do 
agronegócio brasileiro. De acordo com o IBGE (2012) a economia brasileira apresentou um crescimento de 2,7\% em 2011, destes, o setor agropecuário apresentou crescimento anual de 3,9\%, seguida por serviços 2,7\% e indústria 1,6\%.

Dados do Ministério da Agricultura, Pecuária e Abastecimento (2012) comprovam o crescimento e representatividade do agronegócio na economia brasileira por meio do Produto Interno Bruto (PIB) do setor. No período de 2000 a 2010, houve um crescimento médio anual de 3,67\%, enquanto o PIB geral do país avançou 3,59\%. O Brasil se destaca na liderança mundial da produção e exportação de vários produtos agropecuários, como café, açúcar, etanol de cana-de-açúcar, suco de laranja e lidera o ranking das vendas externas do complexo da soja (MAPA, 2012).

Destaca-se nesse contexto a relevância do setor rural e do agronegócio para o desenvolvimento sustentável do país e sua expressiva participação na economia. As entidades cooperativas são representadas por 1.548 entidades, que possuem aproximadamente 943.054 milhões de associados e empregam diretamente 146.011 empregados (OCB, 2012). O Estado de Santa Catarina se destaca por possuir 25\% das cooperativas de todo o Brasil, sendo 53 cooperativas do ramo agropecuário (OCESC, 2012).

Nesse contexto, o estudo visa responder a seguinte problemática de pesquisa: Qual o nível de conformidade dos critérios de mensuração e evidenciação dos ativos biológicos e produtos agrícolas de Cooperativas de Santa Catarina em relação ao Pronunciamento Técnico CPC 29? O objetivo do estudo é evidenciar se as práticas contábeis adotadas por Cooperativas Agropecuárias do Estado de Santa Catarina atendem às exigências do Pronunciamento Técnico CPC 29 - Ativos Biológicos e Produtos Agrícolas.

Dessa forma, a relevância do estudo se justifica pelas recentes alterações ocorridas na mensuração e evidenciação dos itens patrimoniais classificados a partir do CPC 29 como ativos biológicos e produtos agrícolas, bem como, pela significância da atuação das entidades cooperativas agropecuárias para a economia brasileira.

\section{REFERENCIAL TEÓRICO}

Neste item apresenta-se a abordagem do Pronunciamento Técnico CPC 29 (2009), referente às características dos ativos biológicos e produtos agrícolas, bem como, de achados anteriores que contribuem com a temática estudada.

\subsection{Pronunciamento Técnico CPC 29: Ativos Biológicos e Produtos Agrícolas}

No Brasil, os ativos biológicos e produtos agrícolas são regulamentados, pelo Pronunciamento Técnico CPC 29, aprovado pelo CFC por meio da NBC T 19.29, Resolução no 1.186 de 2009. O CPC 29 (2009, p. 2) evidencia que “o objetivo deste Pronunciamento é estabelecer o tratamento contábil, e as respectivas divulgações, relacionados aos ativos biológicos e aos produtos agrícolas". 
O CPC 29 (2009) estabelece que a entidade deve reconhecer um ativo biológico ou produto agrícola somente quando é um recurso controlado pela entidade como resultado de eventos passados, dos quais se espera ou seja provável que fluirão benefícios econômicos futuros associados ao ativo e o valor justo ou o custo do ativo possa ser mensurado com confiabilidade. Ainda, o CPC $29(2009$, p. 3) apresenta o entendimento das características e composição dos itens considerados ativos biológicos e produtos agrícolas:

Produção agrícola é o produto colhido de ativo biológico da entidade.

Ativo biológico é um animal e/ou uma planta, vivos.

Transformação biológica compreende o processo de crescimento, degeneração, produção e procriação que causam mudanças qualitativa e quantitativa no ativo biológico.

De acordo com Rech e Oliveira (2011) para que um elemento possa ser reconhecido nas demonstrações financeiras, primeiramente, é necessário que o mesmo possa ser identificado com base nos atributos em que ele será apresentado.

Nesse sentido, quanto à mensuração devem ser observados critérios distintos para os ativos biológicos e produtos agrícolas. O CPC 29 (2009) estabelece que os ativos biológicos sejam mensurados ao valor justo menos o custo das vendas, no momento do reconhecimento inicial e no final de cada período de competência, exceto para os casos em que o valor justo não pode ser mensurado de forma confiável. O produto agrícola colhido de ativos biológicos de uma entidade deverá ser mensurado ao valor justo, menos os custos das vendas identificados até o momento da colheita.

O Pronunciamento Técnico CPC 29 (2009, p. 5) orienta que os ativos biológicos podem ser analisados e avaliados pelo valor contábil ou seu valor justo:

Valor contábil é o montante pelo qual um ativo é reconhecido no balanço.

Valor justo é o valor pelo qual um ativo pode ser negociado, ou um passivo liquidado, entre partes interessadas, conhecedoras do negócio e independentes entre si, com a ausência de fatores que pressionem para a liquidação da transação ou que caracterizem uma transação compulsória.

Fioravante et al. (2010) esclarecem que na determinação dos benefícios econômicos futuros, considera-se a mensuração das características físicas do ativo. Quanto ao controle dos ativos biológicos, este pode ser evidenciado com base na propriedade legal sobre o ativo ou por meio de critérios específicos.

Hendriksen e Van Breda (1999) evidenciam que o fair value ou o valor justo se caracteriza por uma combinação de bases para a avaliação adequada de determinados itens patrimoniais, considerando as finalidades específicas e o contexto da atividade. Nesse sentido, Silva et al. (2012) ressalta que as demonstrações contábeis devem refletir os valores que estão sendo praticados no local onde as negociações ocorrem, considerando as peculiaridades próprias no caso de atividades 
distribuídas geograficamente. Para Holtz e Almeida (2013) a mensuração dos ativos biológicos e dos produtos agrícolas pelo seu valor justo caracteriza-se como a principal mudança introduzida pela normativa CPC 29 (2009), contrapondo-se à prática até então usual, de mensurá-los ao custo histórico. Salvo os casos em que não haja mercado ativo, em que é facultado à entidade o uso do custo histórico, mediante informação em nota explicativa incluindo as razões pelas quais não se pode realizar a avaliação ao valor justo.

É importante destacar que de acordo com a IAS 41, um mercado ativo é aquele em que os itens negociados são homogêneos; os compradores e vendedores interessados podem ser encontrados em qualquer ocasião; e os preços estão disponíveis ao público (IASB, 2009). Segundo Fioravante et al. (2010, p. 73) “a não mensuração a valor justo de um ativo biológico pode acarretar impactos relevantes nas demonstrações financeiras de uma companhia quando esse ativo biológico se transformar num produto agrícola no ponto de colheita".

$\mathrm{Na}$ mensuração dos ativos biológicos e produtos agrícolas, adota-se a presunção da capacidade de determinação do valor justo de forma confiável. O Quadro 1 apresenta a hierarquia a ser observada na determinação do valor justo dos ativos biológicos e produtos agrícolas, quanto às situações e os métodos possíveis de serem aplicados:

Quadro 1: Hierarquia para determinação do valor justo

\begin{tabular}{|l|l|}
\hline \multicolumn{1}{|c|}{ Situações } & \multicolumn{1}{c|}{ Métodos aplicáveis } \\
\hline Mercado ativo & Mensuração a valor justo com base neste mercado ativo. \\
\hline \multirow{3}{*}{ Ausência de mercado ativo } & - Preço da transação mais recente; \\
& - Preço de mercado de ativos similares; \\
Preço de mercado indisponível & - Padrões do setor; \\
& Utilização do valor presente do fluxo de caixa esperado, para \\
\hline
\end{tabular}

Fonte: CPC 29 (2009).

Ainda quanto à mensuração do valor justo, Rech e Pereira (2012) ressaltam que a avaliação pelo valor justo tem capacidade de incorporar as condições de mercado, proporcionando informações úteis e relevantes para a tomada de decisão, embora apresente maior grau de subjetividade, devido às estimativas para mensuração.

O Quadro 2 apresenta a interpretação da classificação dos ativos biológicos, produtos agrícolas e produtos resultantes do processamento após a colheita.

Quadro 2: Exemplos de ativos biológicos e produtos agrícolas

\begin{tabular}{|l|l|l|}
\hline Ativos biológicos & Produtos Agrícolas & $\begin{array}{l}\text { Produtos resultantes do processamento } \\
\text { após a colheita }\end{array}$ \\
\hline Carneiros & Lã & Fio, tapete \\
\hline Árvores de uma plantação & Madeira & Madeira serrada \\
\hline Plantas & Algodão/Cana colhida & Fio de algodão, vestimentas/ Açúcar \\
\hline Gado de leite & Leite & Queijo \\
\hline Porcos & Carcaça & Salsichas, presunto \\
\hline
\end{tabular}




\begin{tabular}{|l|l|l|}
\hline Arbustos & Folhas & Chá, tabaco \\
\hline Videiras & Uvas & Vinho \\
\hline Árvores frutíferas & Frutas colhidas & Frutas processadas \\
\hline
\end{tabular}

Fonte: CPC 29 (2009, p. 2).

Pode-se observar-se no Quadro 2, que o conjunto de animais e plantas vivos são classificados como ativos biológicos, os produtos agrícolas são aqueles resultantes da produção agrícola ou zootécnica e o terceiro grupo são resultados do processamento de origem biológica ou os produtos agroindustrializados.

Para a evidenciação dos ativos biológicos o CPC 29 (2009) indica que devem ser apresentados como consumíveis e de produção, e classificados em maduros e imaturos. Os ativos apresentados como consumíveis são aqueles que se transformam em produtos agrícolas, enquanto os ativos de produção resultam em novos produtos agrícolas. Os ativos biológicos maduros são aqueles que estão prontos para serem colhidos, ou em condições de gerar novos produtos agrícolas, no entanto, após colheita ou abate tornam-se produtos agrícolas, até que sejam transformados ou beneficiados, gerando outros produtos conforme evidencia o Quadro 2.

De acordo com Silva et al. (2012) as mudanças na divulgação das informações contábeis, exigem maior conhecimento do profissional contábil, e as discussões sobre os ativos biológicos passam pela subjetividade e assimetria da informação contábil, visando a evidenciação de informações úteis e confiáveis para os diversos usuários da contabilidade.

\subsection{Estudos Correlatos}

Os estudos sobre ativos biológicos e produtos agrícolas no Brasil são recentes, após as publicações da IAS 41 (2001) e CPC 29 (2009). Verificou-se que alguns estudos como o de Rech et al. (2006); Lefter e Roman (2007); Brito (2010); Wanderley, Leal e Silva (2011); Silva et al. (2012); Gonçalves, Santos e Szuster (2012), Dallabona, Mazzioni e Klann (2012) contribuem para esclarecer e evidenciar os critérios utilizados na evidenciação dos ativos biológicos e produtos agrícolas.

Rech et al. (2006) analisaram com base na IAS 41 a aplicação dos conceitos de reconhecimento, mensuração e evidenciação dos requisitos exigidos pela norma, no segmento de pecuária de corte. O estudo verificou que o método de valor justo é aplicável a pecuária de corte pela existência de um mercado ativo, onde os produtos são homogêneos e as negociações são frequentes, o que facilita e permite a análise com base em valores de mercado ativo.

Lefter e Roman (2007) estudaram as mudanças de padrão com a emissão da IAS 41 das empresas da Romênia, o que representa o ponto de partida de transição consistente, a partir do princípio do custo de compra para uma contabilidade de valor justo. Os autores evidenciam que a IAS 41 é uma norma específica para o setor econômico da agricultura, ramo importante nos países em desenvolvimento, a sua utilização na divulgação das demonstrações financeiras possibilita apreciar o 
desempenho da gestão a partir da comparação dos valores justos com as realidades atuais do mercado.

O estudo de Brito (2010) teve por objetivo estudar a subjetividade encontrada na aplicação do valor justo na mensuração dos ativos biológicos na atividade pecuária bovina no Brasil, a partir dos aspectos conceituais e as regras determinadas pelo Pronunciamento técnico CPC 29. Os resultados da pesquisa indicam a aplicação do valor justo na atividade agropecuária, todavia ressaltam que em algumas fases da vida do animal, essa aplicação encontra maiores restrições e gera maior subjetividade.

A pesquisa de Wanderley, Leal e Silva (2011) analisou os procedimentos adotados pelas empresas do agronegócio brasileiro: JBS, Brasil Foods (BRF) e Marfrig Group; visando contemplar o objetivo de avaliar o grau de observância das disposições contidas no Pronunciamento Técnico CPC 29, em relação aos ativos biológicos. Os resultados indicam que as empresas ainda não cumpriam as exigências do CPC 29.

Silva et al. (2012) analisaram os requisitos de divulgação do CPC 29 nas empresas de capital aberto e fechado do setor de agronegócio. $\mathrm{O}$ estudo concluiu que a utilização do valor justo como base de mensuração foi utilizado em grande parte da amostra estudada, mas os autores enfatizam a precariedade das demais informações, inclusive das premissas do método adotado.

Gonçalves, Santos e Szuster (2012) realizaram uma pesquisa nas empresas listadas na BM\&FBOVESPA que compõe o setor econômico de consumo, verificando o nível de evidenciação dos ativos biológicos nas demonstrações financeiras. Concluíram que o nível de divulgação das informações é razoável, variando de $54 \%$ a 93\%, porém informações simples exigidas pelo CPC 29 foram pouco divulgadas e o nível de divulgação não evoluiu se comparadas as demonstrações financeiras apresentadas em dezembro de 2010 e setembro de 2011.

O estudo de Dallabona, Mazzioni e Klann (2012) analisou a influência do isomorfismo coercitivo decorrentes da adoção das IFRS em relação aos produtos agrícolas e ativos biológicos das empresas da BM\&FBovespa. A pesquisa é realizada a partir da análise de conteúdo das notas explicativas e o tratamento dos dados é realizado com o auxílio da estatística descritiva e regressão linear múltipla. Os resultados do estudo evidenciam que houve isomorfismo coercitivo a partir da adoção do CPC 29, e que houve consistentes melhorias qualitativas das informações, relacionadas aos critérios de evidenciação dos ativos biológicos para os diversos usuários da contabilidade, justificadas pela obrigatoriedade da adoção do CPC 29 para as empresas analisadas, considerando que o fator tempo foi a variável preponderante do estudo. 


\section{PROCEDIMENTOS METODOLÓGICOS}

A pesquisa se caracteriza como descritiva, pois analisa as particularidades do tratamento contábil e a divulgação das informações relacionadas aos ativos biológicos e produtos agrícolas das Cooperativas Agropecuárias de Santa Catarina. Caracteriza-se ainda, como um estudo com análise documental e qualitativa dos dados, por meio do conjunto de relatórios anuais elaborados por cada entidade cooperativa.

A identificação das Cooperativas Agropecuárias do Estado de Santa Catarina foi feita junto a Organização das Cooperativas do Estado de Santa Catarina - OCESC. Identificou-se 53 cooperativas que atuam no ramo agropecuário. Desta população, foram excluídas as cooperativas de produtores e agricultores, e as cooperativas com faturamento inferior a $\mathrm{R} \$ 15$ milhões de reais, visando comparar as características de evidenciação das entidades cooperativas pesquisadas.

Portanto, passaram a integrar a amostra inicial do estudo 14 entidades que foram consultadas no mês de dezembro de 2012, período em que foram solicitados aos profissionais contábeis responsáveis, o conjunto de demonstrações financeiras e as notas explicativas referentes ao ano de 2011. A amostra final do estudo é composta por nove entidades Cooperativas que disponibilizaram as informações contábeis para consulta e análise.

Após o recebimento das informações financeiras, no mês de janeiro de 2013 foi realizada a análise qualitativa das informações contidas nos relatórios anuais. Utilizou-se o modelo de check list elaborado por Silva et al. (2012) visando identificar se os critérios de divulgação utilizados pelas entidades Cooperativas Agropecuárias de Santa Catarina atendem ao Pronunciamento Técnico CPC 29.

A análise da divulgação das informações coletadas consiste em identificar a quantidade de cooperativas que atendeu cada um dos itens analisados, incluída na coluna "sim" quando o item analisado atender as determinações exigidas pelo CPC 29; e na coluna "não" demonstram-se quantas cooperativas não observaram as exigências do Pronunciamento Técnico CPC 29. A análise realizada apresenta a frequência absoluta e a frequência relativa das respostas da amostra pesquisada visando atingir o objetivo proposto.

Uma limitação atribuída ao estudo decorre do uso da estratégia de análise de conteúdo para avaliar o grau de evidenciação de informações contábeis relativas ao CPC 29 (2009), haja vista que pode haver um elevado índice de subjetividade e/ou juízo de valor na interpretação e análise dos dados, podendo influenciar, de uma forma ou de outra, os resultados obtidos.

Outra limitação diz respeito ao enquadramento dos itens considerados "não" evidenciados. Em determinados casos, é possível a cooperativa não possuir tal item, acarretando tal enquadramento. Assim, os resultados negativos devem ser avaliados com certa cautela. 


\section{APRESENTAÇÃO E DISCUSSÃO DOS RESULTADOS}

Inicialmente identificou-se a localização e as características que delimitaram a seleção da amostra, quanto ao faturamento e ao número de associados, visando evidenciar a representatividade econômica e social destas entidades. Observa-se no Quadro 3 o volume de receitas que as Cooperativas pesquisadas movimentaram no ano base de 2011, bem como o número de associados e de colaboradores que possuíam no mês de dezembro de 2011.

Salienta-se a representatividade dessas entidades no contexto do desenvolvimento do Estado de Santa Catarina, principalmente para a região oeste, bem como, na geração de empregos e renda direta e indireta, tanto para os cooperados como para a comunidade onde se inserem.

Quadro 3: Cooperativas que correspondem a amostra da pesquisa

\begin{tabular}{|l|c|c|c|c|}
\hline COOPERATIVA & MUNICÍPIO & $\begin{array}{c}\text { RECEITAS 2011 } \\
\text { (milhares de reais) }\end{array}$ & ASSOCIADOS & $\begin{array}{c}\text { COLABORADORES } \\
\text { (empregos diretos) }\end{array}$ \\
\hline AURORA & Chapecó & 3.905 .895 & 70.000 & 15.645 \\
\hline COOPERALFA & Chapecó & 1.247 .882 & 15.423 & 2.227 \\
\hline COPERCAMPOS & Campos Novos & 591.445 & 1.058 & 761 \\
\hline COOPER A1 & Palmitos & 576.068 & 7.084 & 897 \\
\hline COPÉRDIA & Concórdia & 421.055 & 8.948 & 614 \\
\hline AURIVERDE & Cunha Porã & 265.528 & 3.855 & 325 \\
\hline COOPERITAIPÚ & Pinhalzinho & 229.990 & 2.129 & 291 \\
\hline COOPERVIL & Videira & 113.568 & 1.262 & 36 \\
\hline CASLO & $\begin{array}{c}\text { São Lourenço do } \\
\text { Oeste }\end{array}$ & 18.674 & 650 & 21.001 \\
\hline TOTAL & 9 & 7.370 .105 & 110.409 & \\
\hline
\end{tabular}

Fonte: OCESC (2012).

A partir das demonstrações financeiras e notas explicativas de cada entidade identificou-se a natureza dos ativos biológicos e dos produtos agrícolas que as entidades cooperativas pesquisadas evidenciam, conforme apresenta o Quadro 4:

Quadro 4: Caracterização dos ativos biológicos e o produtos agrícolas

\begin{tabular}{|l|l|l|}
\hline COOPERATIVAS & \multicolumn{1}{|c|}{ ATIVOS BIOLÓGICOS } & \multicolumn{1}{|c|}{ PRODUTOS AGRÍCOLAS } \\
\hline COOPERALFA & $\begin{array}{l}\text { Suínos; reprodutores e matrizes suínas; } \\
\text { aves; }\end{array}$ & Milho; soja; trigo; feijão; leite. \\
\hline AURORA & $\begin{array}{l}\text { Suínos em formação; matrizes em formação; } \\
\text { aves em formação leitões em formação; } \\
\text { matrizes, reprodutores suínos em comodato; }\end{array}$ & $\begin{array}{l}\text { Milho; soja; trigo; feijão; leite; } \\
\text { laranja; }\end{array}$ \\
\hline COOPER A1 & Suínos; aves; & Milho; soja; trigo; feijão; aveia; \\
\hline COOPERCAMPOS & Suínos; & Milho; soja; trigo; feijão; \\
\hline COPERDIA & Suínos; & \\
\hline
\end{tabular}




\begin{tabular}{|l|l|l|} 
AURIVERDE & Suínos; aves; bovinos; & $\begin{array}{l}\text { Milho; soja; trigo; feijão; leite; } \\
\text { aveia; }\end{array}$ \\
\hline COOPER ITAIPÚ & Suínos em parceria; leitões; bovinos; & Milho; soja; trigo; feijão; leite; \\
\hline COOPERVIL & Suínos; & Milho; soja. \\
\hline CASLO & Suínos; aves; & Milho; soja; leite. \\
\hline
\end{tabular}

Fonte: Dados da pesquisa.

O Quadro 4 demonstra que todas as cooperativas agropecuárias (100\%), trabalham com a atividade suinícola, classificando-os como ativos biológicos, seguido pela avicultura, correspondente a 56\%. Observou-se também, em menor escala, a bovinocultura.

Quanto à natureza dos produtos agrícolas, $88 \%$ das cooperativas produzem em parceria com os associados, milho e soja, além de $67 \%$ das cooperativas produzirem feijão e trigo, 56\% trabalharem com a atividade leiteira, considerando-se estes os produtos agrícolas mais representativos.

Observa-se que apenas uma das cooperativas da amostra não evidenciou os tipos de produtos agrícolas que compõem seus estoques, embora a exemplo das demais entidades pesquisadas seja inerente às suas atividades este tipo de estoque, tendo em vista o processo de estocagem e posterior beneficiamento para a alimentação dos animais citados como ativos biológicos, conforme apresenta o Quadro 4.

A Tabela 1 evidencia que todas as cooperativas agropecuárias classificam parte de seus ativos biológicos e produtos agrícolas no ativo circulante. Em tese, presume-se que sejam ativos biológicos consumíveis e maduros, pois se apresentam disponíveis para a venda, ou passíveis de venda, de acordo com as orientações do CPC 29 (2009).

Identificou-se, ainda, que uma das cooperativas divulga os ativos biológicos no grupo ativo não circulante como realizável a longo prazo, portanto, presume-se que este ativo seja imaturo (não está pronto para ser comercializado). Ressalta-se ainda que $50 \%$ das cooperativas divulgam ativos biológicos no ativo não circulante no grupo imobilizado, correspondentes as matrizes e reprodutores, mantidos com a finalidade de reprodução, conforme orienta o CPC 29 (2009).

Tabela 1: Classificação dos ativos biológicos e produtos agrícolas no balanço patrimonial

\begin{tabular}{c|c|c|c|c|c}
\hline \multirow{2}{*}{ Cooperativas } & Classificação & $\begin{array}{l}\text { Ativo } \\
\text { Circulante }\end{array}$ & $\begin{array}{l}\text { Ativo não } \\
\text { Circulante/ } \\
\text { Realizável a } \\
\text { Longo Prazo }\end{array}$ & $\begin{array}{l}\text { Ativo não } \\
\text { Circulante/ } \\
\text { Imobilizado }\end{array}$ & $\begin{array}{l}\text { \% Sobre } \\
\text { Ativo Total }\end{array}$ \\
\hline \multirow{3}{*}{ Cooperalfa } & Ativos biológicos & 2.083 .929 & - & 2.896 .059 & $1 \%$ \\
\cline { 2 - 7 } & $\begin{array}{l}\text { Produtos } \\
\text { agrícolas }\end{array}$ & 23.216 .596 & & - & $2 \%$ \\
\hline \multirow{3}{*}{ Aurora } & Ativos biológicos & 204.688 .000 & 5.910 .000 & - & $11 \%$ \\
\cline { 2 - 7 } & $\begin{array}{c}\text { Produtos } \\
\text { agrícolas }\end{array}$ & - & - & - & $0 \%$ \\
\hline
\end{tabular}




\begin{tabular}{|c|c|c|c|c|c|}
\hline \multirow[b]{2}{*}{ Cooper A1 } & Ativos biológicos & 13.548 .818 & - & 10.946 .845 & $5 \%$ \\
\hline & $\begin{array}{l}\text { Produtos } \\
\text { agrícolas }\end{array}$ & 10.427 .721 & - & 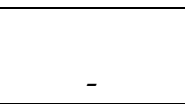 & $2 \%$ \\
\hline \multirow[b]{2}{*}{$\begin{array}{c}\text { Coopercampo } \\
\mathrm{s}\end{array}$} & Ativos biológicos & 19.229 .487 & - & 3.505 .568 & $4 \%$ \\
\hline & $\begin{array}{l}\begin{array}{l}\text { Produtos } \\
\text { agrícolas }\end{array} \\
\end{array}$ & 9.804 .492 & - & (1) & $2 \%$ \\
\hline \multirow[b]{2}{*}{ Copérdia } & Ativos biológicos & 12.849 .572 & - & - & $4 \%$ \\
\hline & $\begin{array}{l}\text { Produtos } \\
\text { agrícolas }\end{array}$ & 27.287 .529 & & - & $8 \%$ \\
\hline \multirow[b]{2}{*}{ Auriverde } & Ativos biológicos & 9.155 .454 & - & 1.622 .328 & $6 \%$ \\
\hline & \begin{tabular}{|l|} 
Produtos \\
agrícolas
\end{tabular} & 3.141 .099 & - & - & $2 \%$ \\
\hline \multirow[b]{2}{*}{ Cooper Itaipú } & Ativos biológicos & 5.146 .175 & - & 2.137 .434 & $4 \%$ \\
\hline & \begin{tabular}{|l|} 
Produtos \\
agrícolas
\end{tabular} & 1.270 .188 & - & - & $1 \%$ \\
\hline \multirow[b]{2}{*}{ Coopervil } & Ativos biológicos & 4.214 .163 & - & - & $4 \%$ \\
\hline & \begin{tabular}{|l|} 
Produtos \\
agrícolas
\end{tabular} & 1.529 .383 & - & - & $2 \%$ \\
\hline \multirow[b]{2}{*}{ Caslo } & Ativos biológicos & - & - & - & $0 \%$ \\
\hline & \begin{tabular}{|l|} 
Produtos \\
agrícolas
\end{tabular} & 154.938 & - & - & $1 \%$ \\
\hline TOTAL & - & 347.747 .544 & 5.910 .000 & 21.108 .234 & $4 \%$ \\
\hline
\end{tabular}

Fonte: Dados da pesquisa.

Com base na pesquisa realizada a partir das informações financeiras das Cooperativas Agropecuárias de Santa Catarina, analisaram-se os critérios de mensuração e evidenciação dos ativos biológicos e produtos agrícolas a partir das exigências do CPC 29 no intuito de constatar se as práticas contábeis adotadas pelas Cooperativas atendem as recomendações. A Tabela 2 apresenta os itens divulgados nas demonstrações contábeis e notas explicativas das Cooperativas analisadas:

Tabela 2 - Listagem de itens de divulgação determinados pelo CPC 29

\begin{tabular}{|c|c|c|c|c|c|}
\hline & $\begin{array}{l}\text { Itens do CPC } 29 \text { referentes à divulgação de ativos biológicos } \\
\text { e produtos agrícolas }\end{array}$ & Sim & $\%$ & Não & $\%$ \\
\hline 1) & $\begin{array}{l}\text { Há divulgação de ganho ou perda do período em relação } \\
\text { (apresentação dos saldos inicial e final do período): }\end{array}$ & & & & \\
\hline a) & ao valor do ativo biológico? & 3 & $33 \%$ & 6 & $67 \%$ \\
\hline b) & ao produto agrícola? & 4 & $44 \%$ & 5 & $56 \%$ \\
\hline c) & $\begin{array}{l}\text { à mudança no valor justo, menos a despesa de venda dos ativos } \\
\text { biológicos? }\end{array}$ & 0 & $0 \%$ & 9 & $100 \%$ \\
\hline 2) & $\begin{array}{l}\text { Há descrição de cada grupo de ativos biológicos e produtos } \\
\text { agrícolas? }\end{array}$ & 8 & $89 \%$ & 1 & $11 \%$ \\
\hline 3) & Há distinção entre os ativos biológicos: & & & & \\
\hline a) & consumíveis e de produção? & 0 & $0 \%$ & 9 & $100 \%$ \\
\hline b) & maduros e imaturos? & 0 & $0 \%$ & 9 & $100 \%$ \\
\hline 4) & $\begin{array}{l}\text { Há divulgação da natureza das atividades envolvendo cada grupo } \\
\text { de ativos biológicos? }\end{array}$ & 8 & $89 \%$ & 1 & $11 \%$ \\
\hline
\end{tabular}




\begin{tabular}{|c|c|c|c|c|c|}
\hline 5) & $\begin{array}{l}\text { Há divulgação de mensurações ou estimativas não-financeiras de } \\
\text { quantidade físicas: }\end{array}$ & & & & \\
\hline a) & de cada grupo de ativos biológicos no final do período? & 6 & $67 \%$ & 3 & $33 \%$ \\
\hline b) & da produção agrícola durante o período? & 6 & $67 \%$ & 3 & $33 \%$ \\
\hline 6) & $\begin{array}{l}\text { Há informações sobre o método e as premissas significativas } \\
\text { aplicados na determinação do valor justo de cada grupo de produto } \\
\text { agrícola no momento da colheita e de cada grupo de ativos } \\
\text { biológicos? }\end{array}$ & 2 & $22 \%$ & 7 & $78 \%$ \\
\hline 7) & $\begin{array}{l}\text { Há divulgação do valor justo, menos a despesa de venda do produto } \\
\text { agrícola colhido durante o período, determinado no momento da } \\
\text { colheita? }\end{array}$ & 4 & $44 \%$ & 5 & $56 \%$ \\
\hline 8) & Há informação sobre: & & & & \\
\hline a) & $\begin{array}{l}\text { a existência e o total de ativos biológicos cuja titularidade legal seja } \\
\text { restrita? }\end{array}$ & 3 & $33 \%$ & 6 & $67 \%$ \\
\hline b) & $\begin{array}{l}\text { a existência e o total dos produtos agrícolas cuja titularidade seja } \\
\text { restrita? }\end{array}$ & 6 & $67 \%$ & 3 & $33 \%$ \\
\hline 9) & $\begin{array}{l}\text { Há divulgação do montante de ativos biológicos dados como } \\
\text { garantia de exigibilidades? }\end{array}$ & 2 & $22 \%$ & 7 & $78 \%$ \\
\hline 10) & $\begin{array}{l}\text { Há informações sobre o montante de compromissos relacionados } \\
\text { com o desenvolvimento ou aquisição de ativos biológicos? }\end{array}$ & 8 & $89 \%$ & 1 & $11 \%$ \\
\hline 11) & $\begin{array}{l}\text { Há divulgação das estratégias de administração de riscos financeiros } \\
\text { relacionadas com a atividade agrícola? }\end{array}$ & 6 & $67 \%$ & 3 & $33 \%$ \\
\hline 12) & $\begin{array}{l}\text { Há conciliação das mudanças no valor contábil de ativos biológicos } \\
\text { entre o início e o fim do período corrente? }\end{array}$ & 5 & $56 \%$ & 4 & $44 \%$ \\
\hline 13) & Se, sim, a conciliação inclui: & & & & \\
\hline a) & $\begin{array}{l}\text { ganho ou perda decorrente da mudança no valor justo menos a } \\
\text { despesa de venda? }\end{array}$ & 5 & $56 \%$ & 4 & $44 \%$ \\
\hline 14) & Se, sim, a conciliação inclui: & & & & \\
\hline a) & aumentos devido às compras? & 5 & $56 \%$ & 4 & $44 \%$ \\
\hline b) & $\begin{array}{l}\text { reduções atribuíveis às vendas e aos ativos biológicos classificados } \\
\text { como mantidos para venda ou incluídos em grupo de ativos } \\
\text { mantidos para essa finalidade? }\end{array}$ & 5 & $56 \%$ & 4 & $44 \%$ \\
\hline c) & reduções devidas às colheitas? & 0 & $0 \%$ & 9 & $100 \%$ \\
\hline d) & aumento resultante de combinação de negócios? & 1 & $11 \%$ & 8 & $89 \%$ \\
\hline e) & $\begin{array}{l}\text { diferenças cambiais líquidas decorrentes de conversão das } \\
\text { demonstrações contábeis para outra moeda de apresentação? }\end{array}$ & 0 & $0 \%$ & 9 & $100 \%$ \\
\hline f) & $\begin{array}{l}\text { e, também, do oposto, ou seja, de conversão de operações em moeda } \\
\text { estrangeira para a moeda de apresentação das demonstrações da } \\
\text { entidade? }\end{array}$ & 0 & $0 \%$ & 9 & $100 \%$ \\
\hline 15) & $\begin{array}{l}\text { Há divulgação separada do total da mudança no valor justo menos a } \\
\text { despesa de venda dos ativos biológicos decorrentes de mudanças } \\
\text { físicas e de alterações de preços no mercado, incluído no resultado? }\end{array}$ & 1 & $11 \%$ & 8 & $89 \%$ \\
\hline 16) & Se, sim, as informações são por: & & & & \\
\hline a) & grupo/conta/tipo de ativo? & 0 & $0 \%$ & 9 & $100 \%$ \\
\hline 17) & $\begin{array}{l}\text { A entidade mensura ativos biológicos pelo custo, menos qualquer } \\
\text { depreciação e perda no valor recuperável acumuladas? }\end{array}$ & 8 & $89 \%$ & 1 & $11 \%$ \\
\hline 18) & Se, sim, divulga: & & & & \\
\hline
\end{tabular}




\begin{tabular}{l|l|c|c|c|c}
\hline a) & descrição dos ativos biológicos e/ou produtos agrícolas? & 6 & $67 \%$ & 3 & $33 \%$ \\
\hline b) & $\begin{array}{l}\text { explicação da razão pela qual o valor justo não pode ser mensurado } \\
\text { de forma confiável? }\end{array}$ & 0 & $0 \%$ & 9 & $100 \%$ \\
\hline c) & $\begin{array}{l}\text { se possível, uma faixa de estimativas dentro da qual existe alta } \\
\text { probabilidade de se encontrar o valor justo? }\end{array}$ & 0 & $0 \%$ & 9 & $100 \%$ \\
\hline d) & o método de depreciação utilizado? & 5 & $56 \%$ & 4 & $44 \%$ \\
\hline e) & a vida útil ou a taxa de depreciação utilizada? & 3 & $33 \%$ & 6 & $67 \%$ \\
\hline f) & $\begin{array}{l}\text { o total bruto e a depreciação acumulada (adicionada da perda por } \\
\text { irrecuperabilidade acumulada) no início e no final do período? }\end{array}$ & 4 & $44 \%$ & 5 & $56 \%$ \\
\hline g) & $\begin{array}{l}\text { ganho ou perda reconhecido sobre a venda de ativos biológicos } \\
\text { mantidos pelo custo? }\end{array}$ & 0 & $0 \%$ & 9 & $100 \%$ \\
\hline h) & perdas irrecuperáveis? & 0 & $0 \%$ & 9 & $100 \%$ \\
\hline i) & reversão de perdas no valor recuperável? & 0 & $0 \%$ & 9 & $100 \%$ \\
\hline j) & depreciação? & 5 & $56 \%$ & 4 & $44 \%$ \\
\hline 19) & $\begin{array}{l}\text { A menção de ativos biológicos previamente mensurados pelo custo, } \\
\text { menos qualquer depreciação e perda de valor recuperável que se } \\
\text { tornaram mensuráveis pelo valor justo? }\end{array}$ & & & \\
\hline 20) & Se, sim: & 0 & $0 \%$ & 9 & $100 \%$ \\
\hline a) & Há uma descrição dos ativos biológicos? & & & \\
\hline 21) & Se, sim: & 0 & $0 \%$ & 9 & $100 \%$ \\
\hline & há uma explicação da razão pela qual a mensuração do valor justo se \\
tornou mensurável de forma confiável? & 0 & $0 \%$ & 9 & $100 \%$ \\
\hline 22) & Se, sim: & & & \\
\hline a) & há informaçães sobre o efeito da mudança? & & & \\
\hline
\end{tabular}

Fonte: adaptado de Silva et. al. (2012)

De acordo com a Tabela 2, no que tange a mensuração dos ativos biológicos e produtos agrícolas, apenas 33\% das cooperativas estão divulgando o ganho ou perda do período em relação aos ativos biológicos e $44 \%$ em relação aos produtos agrícolas. Nenhuma das entidades evidenciou ganho ou perda por mudanças no valor justo menos as despesas de vendas dos ativos biológicos.

Neste aspecto os resultados remetem as evidenciações de Dallabona, Mazzioni e Klann (2012), quanto à percepção de melhorias qualitativas nas informações, relacionadas aos critérios de evidenciação dos ativos biológicos, e embora a justificativa seja a obrigatoriedade da adoção do CPC 29, o efeito da mensuração contábil e melhoria do processo de análise e avaliação dos ativos biológicos e produtos agrícolas, reflete na melhoria da evidenciação das informações aos diversos usuários das informações contábeis.

Quanto à divulgação da natureza das atividades envolvendo cada grupo de ativos biológicos, $89 \%$ das Cooperativas indicam a natureza e as características desses ativos. Embora não houve distinção por parte de nenhuma cooperativa entre os ativos biológicos consumíveis e de produção, maduros e imaturos, conforme orienta o CPC 29. 
Identificou-se ainda no relatório anual e nas notas explicativas, a divulgação de estimativas não financeiras de quantidades físicas em $67 \%$ das cooperativas agropecuárias pesquisadas. As cooperativas apresentaram também um comparativo com os períodos anteriores, evidenciando e possibilitando analisar o crescimento. No entanto, apenas $22 \%$ das cooperativas apresentam os métodos e premissas aplicados na determinação do valor justo de cada grupo de ativos biológicos, considerando que mensuram pelo valor justo, menos as despesas de venda ou custo de produção, não superior ao valor de mercado.

Os resultados corroboram com as considerações de Silva et al. (2012), quanto a precariedade das informações relacionadas as premissas do método adotado (se valor justo, valor presente, etc), investigando empresas de capital aberto e fechado do setor de agronegócio analisadas. Na análise realizada observa-se também a carência da evidenciação dos métodos e premissas utilizadas pelas cooperativas agropecuárias. Pondera-se que muitas entidades utilizam as empresas de capital aberto como parâmetro para a análise das notas explicativas. É possível certa influência do fato das empresas de capital aberto não ter evidenciado tais premissas tenha também seus reflexos em outras empresas, especialmente de segmentos correlacionados, como neste caso.

Para os produtos agrícolas, $44 \%$ das cooperativas divulgaram que os reconheceram pelo valor justo menos as despesas de venda do produto agrícola colhido durante o período, determinado no momento da colheita. As demais cooperativas (56\%) apresentam os produtos agrícolas pelo seu custo de aquisição (histórico), ou não divulgaram os métodos e premissas utilizados para reconhecer e evidenciar os produtos agrícolas.

Da amostra pesquisada, 33\% das cooperativas possuem e divulgam ativos biológicos com titularidade legal restrita. Quanto aos produtos agrícolas $67 \%$ das entidades possuem restrição quanto à titularidade, ocorrida nas situações em que o produto é depositado pelo cooperado aos cuidados da cooperativa (conforme a questão 8 da Tabela 2). Quanto à divulgação dos produtos agrícolas e ativos biológicos dados em garantia de exigibilidades, conclui-se que apenas $22 \%$ divulgam o montante de produtos dados como garantia.

No que tange aos compromissos relacionados com o desenvolvimento ou aquisição de ativos biológicos, $89 \%$ das cooperativas agropecuárias divulgam a provisão de compra de produtos agrícolas já depositados pelos produtores associados na cooperativa. Outras $67 \%$ das entidades divulgam as estratégias da administração para riscos financeiros relacionados com as atividades agrícolas. Neste sentido, destaca-se a participação destas entidades no mercado de derivativos, realizando operações de contratos futuros negociados nas bolsas, ou contratos de venda com os próprios clientes, além de medidas de controle de estoques.

A Tabela 2 ainda demonstra que houve conciliação das mudanças no valor contábil de ativos biológicos entre o início e o fim do período corrente por parte de $56 \%$ das cooperativas participantes da pesquisa. Também, 56\% das cooperativas 
divulgam valores correspondentes ao aumento decorrente das compras e reduções atribuíveis as vendas e aos ativos biológicos classificados como mantidos para venda ou incluídos em grupo de ativos mantidos para essa finalidade. Além destas informações, $11 \%$ apresentam aumento nos ativos biológicos e produtos agrícolas provenientes de combinação de negócios.

Das mudanças incluídas no resultado derivadas de mudanças físicas e alterações dos preços de mercado, apenas uma cooperativa divulga variação negativa, decorrente das mudanças no preço de mercado, considerando que esta informação não é apresentada separadamente por grupo, conta ou tipo de ativo biológico.

Identificou-se que $89 \%$ das cooperativas mensuram os ativos biológicos e produtos agrícolas pelo custo, menos qualquer depreciação e perda no valor recuperável acumulada, ainda, 67\% descrevem quais ativos foram mensurados por estes critérios. No entanto, nenhuma das cooperativas apresenta uma explicação da razão pela qual o valor justo não pode ser mensurado de forma confiável ou apresenta estimativas na possibilidade de se encontrar o valor justo.

Os resultados obtidos quanto ao nível de evidenciação dos ativos biológicos se coadunam com a pesquisa de Gonçalves, Santos e Szuster (2012), quando compararam as empresas da BM\&FBOVESPA do setor econômico de consumo e identificaram um nível de evidenciação dos ativos biológicos entre de 54\% a 93\%. Neste sentido os resultados também se assemelham as considerações dos autores quando observaram que informações simples exigidas pelo CPC 29 foram pouco divulgadas. Neste sentido, os achados evidenciam que embora ocorra a avaliação e evidenciação dos ativos biológicos, em conformidade com o CPC 29, ainda poderiam ser mais bem evidenciadas as informações quanto aos critérios e premissas utilizadas pelas cooperativas para a mensuração desses ativos.

Quanto aos métodos de depreciação utilizados, 56\% das entidades divulgam, destacando-se o método linear apurado com base na estimativa de vida útil no e valor residual recuperável, avaliados por meio de laudo. Porém, apenas 33\% divulgam a vida útil ou a taxa de depreciação utilizada e outros $44 \%$ evidenciam o total da depreciação acumulada e o valor bruto do ativo. Por fim, nenhuma das cooperativas da amostra faz menção aos grupos de ativos biológicos mensurados pelo custo que se tornaram mensuráveis pelo valor justo.

De modo geral, os resultados corroboram os estudos anteriores de Wanderley, Leal e Silva (2011); Silva et al. (2012) e Gonçalves, Santos e Szuster (2012) evidenciando que também as cooperativas agropecuárias ainda estão se adequando ao CPC 29 e o nível de divulgação das informações ainda não atende de forma completa todas as premissas e recomendações quanto aos critérios de reconhecimento, mensuração e evidenciação dos ativos biológicos e produtos agrícolas.

De modo geral, os resultados evidenciam que embora o Pronunciamento Técnico CPC 29 seja relativamente recente, observa-se que de modo geral, as 
cooperativas estão se ajustando. No entanto, ainda não atendem de forma plena as premissas e exigências desta normativa.

\section{CONSIDERAÇÕES FINAIS}

A pesquisa teve como objetivo evidenciar se as práticas contábeis adotadas pelas Cooperativas Agropecuárias do Estado de Santa Catarina atendem às exigências do Pronunciamento Técnico CPC 29 - Ativos Biológicos e Produtos Agrícolas. Por meio das demonstrações financeiras e notas explicativas, identificaram-se os critérios de mensuração e evidenciação dos ativos biológicos e produtos agrícolas das cooperativas da amostra, bem como se estes atendem as exigências do CPC 29.

Observou-se que não houve distinção entre os ativos biológicos consumíveis e de produção ou maduros e imaturos pelas cooperativas pesquisadas, apenas a divulgação em contas patrimoniais distintas (sobretudo nas contas de estoque e imobilizado). No entanto, para fins de análise e interpretações que atendam as condições de distinção dos ativos biológicos é necessária tal separação e classificação, conforme orienta o CPC 29 (2009).

Constatou-se, também, que $89 \%$ das cooperativas mensuram algum tipo de ativos biológicos e produtos agrícolas pelo custo, menos qualquer depreciação e perda no valor recuperável acumulada. No entanto, chama a atenção que nenhuma das cooperativas apresentou uma explicação da razão pela qual o valor justo não pode ser mensurado de forma confiável ou apresenta estimativas na possibilidade de se encontrar o valor justo, conforme orientações do CPC 2009. Assim, as notas explicativas poderiam referenciar as práticas de avaliação adotadas pela entidade, no sentido de buscar alternativas para a avaliação dos ativos biológicos a valor justo, bem como, apresentar justificativa ou explicação da impossibilidade de obter tal informação, remetendo ao atendimento adequado do CPC 29 (2009)

Observam-se as dificuldades e fragilidades no processo de evidenciação dos procedimentos adotados para avaliação dos ativos biológicos, considerando que 56\% das cooperativas observadas mensuraram os produtos agrícolas pelo seu custo de aquisição, ou não divulgaram os métodos e premissas utilizados para a mensuração e evidenciação.

A pesquisa constatou que em conformidade com o CPC 29, quando da incapacidade de mensuração de forma confiável do valor justo, as cooperativas adotaram o critério de mensuração pelo custo de aquisição ou custo histórico. Porém, não são adicionadas a depreciação e as perdas por irrecuperabilidade acumuladas; e algumas cooperativas também não divulgam a vida útil ou a taxa de depreciação utilizada na apresentação do total bruto e líquido. Destaca-se ainda a inexistência de ativos biológicos mensurados pelo custo, menos a depreciação e perda do valor recuperável, que se tornaram mensuráveis pelo valor justo. 
Considerando os aspectos e objetivos do CPC 29, observa-se a partir dos resultados que a maioria das cooperativas da amostra ainda reconhece e evidencia os ativos biológicos e produtos agrícolas de forma tradicional (custo histórico). Alterações na estrutura do plano de contas ocorreram quanto à natureza e forma de classificação, no entanto, ainda não atende as premissas do CPC 29, quanto aos critérios de reconhecimento destes ativos pelo valor justo (com base em mercado ativo) e não mais pelo custo histórico, visando evidenciar tais elementos patrimoniais por valores mais próximos do seu mercado ativo ou de realização.

Os resultados do estudo permitem concluir que o uso do valor justo como método de avaliação dos ativos biológicos e produtos agrícolas ainda não está consolidado nas cooperativas investigadas. Em que pese à existência da premissa teórica de que a avaliação pelo valor justo resulta em uma informação mais relevante para tais itens, as entidades pesquisadas demonstram optar, maioritariamente, pela objetividade do custo de aquisição.

Diante dos resultados, observa-se que o Pronunciamento Técnico CPC 29, vigente desde 2009, ainda não é atendido integralmente pelas cooperativas agropecuárias de Santa Catarina investigadas. Embora estas entidades não estejam obrigadas a divulgação das informações financeiras, as cooperativas representam função importante na economia, inclusive no âmbito internacional. Em sua maioria estão obrigadas a atender ao conjunto completo de Pronunciamentos Contábeis por estarem enquadradas (pelo faturamento) como empresas de grande porte, neste aspecto estariam obrigadas a atender ao conjunto completo de Pronunciamentos Contábeis, para mensurar, avaliar e evidenciar os ativos biológicos e produtos agrícolas.

Recomenda-se que novos estudos contemplem a análise das premissas de mensuração dos ativos biológicos e produtos agrícolas com base no valor justo e a evolução da divulgação dos critérios de mensuração e evidenciação dos ativos biológicos e produtos agrícolas, bem como, se observe as práticas contábeis de outras entidades. 


\section{REFERÊNCIAS}

BRITO, E. Um estudo sobre a subjetividade na mensuração do valor justo da atividade da pecuária bovina. 2010. 109 f. Dissertação (Mestrado em Ciências Contábeis) - Faculdade de Economia, Administração e Contabilidade da Universidade de São Paulo. Ribeirão Preto, 2010.

CPC. COMITÊ DE PRONUNCIAMENTOS CONTÁBEIS. Pronunciamento técnico CPC 29 ativos biológicos e produtos agrícolas. Dispõem sobre o tratamento contábil dos ativos biológicos e produtos agrícolas. 2009. Disponível em <http://www.cpc.org.br/mostraOrientacao.php?id=45> Acesso em: 07 ago. 2012.

DALLABONA, L. F.; MAZZIONI, S.; KLANN, R.C. A Influência do Isomorfismo Coercitivo Decorrente da Adoção das IFRS em Relação à Evidenciação de Ativos Biológicos e Produtos Agrícolas. In: Encontro Internacional sobre Gestão Ambiental e Meio Ambiente, 2012, São Paulo. Anais... São Paulo: XIV ENGEMA, 2012.

ERNST \& YOUNG TERCO; FIPECAFI. IFRS: 1ํo ano, análises sobre a adoção inicial do IFRS no Brasil. Disponível em <http://www.ey.com/Publication/vwLUAssets/FIPECAFI_1_ano_de_IFRS/\$FILE/Fipe cafi_Baixa.pdf> Acesso em 06 ago. 2012.

FIORAVANTE, A. C; VARONI, P; MARTINS, V. A; RIBEIRO, M.S. IAS 41 - ativo biológico e produto agrícola. In: ERNEST\&YOUNG; FIPECAFI. Manual de normas internacionais de contabilidade: IFRS versus normas brasileiras. São Paulo: Atlas, 2010.

GONÇALVES, J. C. SANTOS, L. J.; SZUSTER, N. Evidenciação de ativos biológicos nas demonstrações contábeis: uma análise das empresas do sub-setor de agropecuária e alimentos processados na BM\&FBOVESPA. In: Congresso Nacional de Excelência em Gestão, 8., 2012. Rio de Janeiro - RJ. Anais... Rio de Janeiro: CNEG, 2012. CD-ROM.

HOLTZ, L.; ALMEIDA, J. E. F. Estudo sobre a relevância e a divulgação dos ativos biológicos das empresas listadas na BM\&FBOVESPA. Sociedade, Contabilidade e Gestão, v. 8, n. 2, p. 28-46, 2013.

IBGE. INSTITUTO BRASILEIRO DE GEOGRAFIA E ESTATISTICA. Em 2011, PIB cresce $2,7 \%$ e totaliza $\mathrm{R} \$ 4,143$ trilhões. Disponível em: http://www.ibge.gov.br/home/presidencia/noticias/noticia_visualiza.php?id_noticia= 2093\&id_pagina=1\&titulo=Em-2011,-PIB-cresce-2,7\%-e-totaliza-R\$-4,143-trilhoes. Acesso em : 20 dez. 2012. 
IASB. INTERNATIONAL ACCOUNTING STANDARS BOARD. International Accounting Standard $41-$ Agriculture (IAS 41). Disponível em $<$ http://ifrs.org/Search.html?q=IAS41\&adv=0> Acesso em 15 dez. 2012.

HENDRIKSEN, E. S.; VAN BREDA, M. F. Teoria da contabilidade. São Paulo: Atlas, 1999.

LEFTER, V.; ROMAN, A. G. IAS 41 Agriculture: fair value accounting. Disponível em $<$ http://ideas.repec.org/a/agr/journl/v5(510)y2007i5(510)p1522.html\#download>. Acesso: 20 dez. 2012.

MAPA. MINISTÉRIO DA AGRICULTURA, PECUÁRIA E ABASTECIMENTO. Estatísticas. Disponível em: http://www.agricultura.gov.br/vegetal/estatisticas. Acesso: 20 dez. 2012.

OCB. ORGANIZAÇÃO DAS COOPERATIVAS DO BRASIL. Principais Números/Ações. Disponível em: http://www.ano2012.coop.br/default.php?p=texto.php\&c=quemsomos_principaisnu meros. Acesso: 21 fev. 2013.

OCESC. ORGANIZAÇÃO DAS COOPERATIVAS DO ESTADO DE SANTA CATARINA. Disponível em: http://www.ocesc.org.br/cooperativas/busca.php. Acesso em: 02 dez. 2012.

RECH, I. J.; PEREIRA, I. V.; CUNHA, M. F.; PEREIRA, C. C. IAS 41 - Agriculture: um estudo da aplicação da norma internacional de contabilidade às empresas de pecuária de corte. In: Congresso USP de Controladoria e Contabilidade, 6.. 2006. São Paulo-SP. Anais... São Paulo. FEA/USP, 2006. CD-ROM.

OLIVEIRA, K. G. Análise da Aplicação do CPC 29 e IAS 41 aos Ativos Biológicos no setor de silvicultura. In: V Congresso ANPCONT, 5.; 2011. Vitória - ES. Anais... Vitória: ANPCONT, 2011. CD-ROM.

. PEREIRA, I. V. Valor justo: análise dos métodos de mensuração aplicáveis aos ativos biológicos de natureza fixa. Revista Custos e @gronegócio on line, v. 8, n. 2, p. 131-157, 2012.

SILVA, R. M.; FIGUEIRA, L.; PEREIRA, L.; RIBEIRO, M. S. Processo de convergência as normas internacionais de contabilidade: Uma Análise dos Requisitos de Divulgação do CPC 29. Social Science Research Network. (Feb, 2012). Disponível em: $<$ http://ssrn.com/abstract=2012705. Acesso em: 08 nov. 2012. 
WANDERLEY, C. A. N.; LEAL, R. B.; SILVA, A. C. Tratamento contábil de ativos biológicos e produtos agrícolas: uma análise das principais empresas do agronegócio brasileiro. Revista Pensar Contábil, v. 14, p. 53-62, 2012. 